drug. ${ }^{13}$ A recent review of experience with azathioprine in 27 patients over a median duration of seven years suggested that side effects were few, and treatment had had to be discontinued in only four patients ${ }^{14}$; all of the others improved and were able to take lower dosages of anticholinesterase drugs and corticosteroids. It has been argued that corticosteroids and immunosuppressants do not diminish the already low mortality from myasthenia gravis, ${ }^{8}$ but there is little doubt that they improve the quality of life. ${ }^{14}$

Despite the lack of evidence from rigorous controlled trials the conclusion must be that the outlook for patients with myasthenia gravis has improved considerably over the past

Walker M. Treatment of myasthenia gravis with physostigmine. Lancet 1934;i: 1200-1.

Rowland LP. Controversies about the treatment of myasthenia gravis. 7 Neurol Neurosurg Psychiatry 1980;43:644-59.

3 Oosterhuis HJGH. The natural course of myasthenia gravis: a long term follow up study. F Neurol Neurosurg Psychiatry 1989;52:1121-7.

Simpson JA. Evaluation of thymectomy in myasthenia gravis. Brain 1958;81:112-45.

5 Miller JFAP. Immunological function of the thymus. Lancet 1961;ii:748-9.

6 Grob D, Brunner NG, Namba T. The natural course of myasthenia gravis and effects of various therapeutic measures. Ann NY Acad Sci 1981;377:652-70.

7 Oosterhuis $\mathrm{HJGH}$. Long term effects of treatment in 374 patients with myasthenia gravis. In: de Baets M, Oosterhuis HJGH, Toyka K, eds. Monographs in allergy. Vol 25. Basle: Karger, 1988:75-85.

8 Simpson JA, Thomaides T. Treatment of myasthenia gravis: an audit. $O \mathcal{F}$ Med 1987;64:693-704 decade. The judicious use of thymectomy, corticosteroids, and, if necessary, the more powerful immunosuppressive drugs offers them a combination of reduced morbidity and a high rate of remission. The mortality from myasthenia gravis in the 1990s should be negligible. We agree with Rowland: the prognosis in myasthenia has improved so much we must be doing something right.

V FONSECA Senior Registrar

C W H HAVARI) Consultant Physician and Endocrinologist

Royal Free Hospital, London NW3 2QG

9 Buckingham JM, Howard FM, Bernatz PE, et al. The value of thymectomy in myasthenia gravis: computer-assisted matched study. Ann Surg 1976;184:453-5.

10 Pascuzzi RM Coslett HB, Johns TR. Long-term corticosteroid treatment of myasthenia gravis: report of 116 patients. Ann Neurol 1984;15:291-8.

11 Havard CWH, Fonseca V. New treatment approaches to myasthenia gravis. Drugs 1990;39:66-73.

12 Mertens HG, Hertel G, Reuther P, Ricker K. Effect of immunosuppressive drugs (azathioprine) Ann NY Acad Sci 1981;377:691-9.

13 Tindall RSA, Rollins JA, Phillips JT, Greenlee RG, Wells L, Belenduick G. Preliminary results of a double-blind, randomised, placebo-controlled trial of cyclosporin in myasthenia gravis. $N$ Engl 7 Med 1987;316:719-24

14 Fonseca $\mathrm{V}$, Havard $\mathrm{CWH}$. Long term treatment of myasthenia gravis with azathioprine. Postgrad Med f 1990;66:102-5.

\title{
Human Fertilisation and Embryology Bill goes to report stage
}

\author{
Donor anonymity to go? Is GIFT included?
}

The Human Fertilisation and Embryology Bill has now completed its committee stage and will shortly return to the House of Commons for report. It has come out of committee containing two major ambiguities. These must be resolved before the bill becomes law.

\section{Donor anonymity}

The first concerns anonymity for semen donors. Nearly half of all infertility is caused by problems in the man, notably deficient concentration and quality of spermatozoa or total lack of spermatozoa.' Our limited understanding about the factors controlling spermatogenesis means that there are no reliable medical or surgical treatments for these conditions. For a small number of couples sufficient motile sperm may be recovered from the ejaculate to allow an egg to be inseminated in vitro. The quality of the sperm may, however, be so poor that fertilisation does not occur. For these unfortunate couples, and for those couples in which the man is azoospermic, the only treatment by which a pregnancy can be achieved is that by donor insemination.

Spermatozoa are donated anonymously for insemination by fertile men who wish to help infertile couples to have a child. Clinics offering donor insemination take great care to match the physical characteristics of the infertile male partner to those of the donor and to screen potential donors for sexually transmissible agents (including HIV) and genetically carried disease $^{2-4}$ The anonymity of these individual donors has always been carefully protected. The Human Fertilisation and Embryology Bill requires all donor insemination centres to be licensed and to store in the files of the newly created licensing authority identifying information about any person whose gametes are used for any assisted conception procedure including donor insemination. Failure to comply constitutes a breach of the criminal law. The intentions of this proposed regulation are clear and admirable and follow recommendations in the Warnock report. ${ }^{5}$ Firstly, it will enable standards of practice, including counselling, to be set and monitored and accurate statistics about donor insemination in this country to be collected. ${ }^{+}$Secondly, if a child born after donor insemination should be found to have a genetic disease then insemination of other patients using the same sperm may be prevented, and the donor can be traced and advised of the risk that he might have of passing on a genetic disease to his own offspring. Indeed, clinics practising donor insemination already keep detailed and totally confidential records of births and donors for this specific eventuality. But the bill also allows for a new practice. A child born after donor insemination on reaching the age of 18 years may request information about his or her genetic origins. Despite assurances by the minister in committee that the intention of the law was to provide only non-identifying information to the child-as was recommended by the Warnock committee and in the government white paper-an amendment to include the wording "non-identifying" was defeated in committee. ${ }^{6}$ Thus the law as it now stands does not preclude identifying information about the donor being released by the licensing authority.

Opinions are polarised as to whether this new lack of guaranteed anonymity for donors is a good or a bad thing. ${ }^{78}$ On the one hand there is a body of opinion that holds strongly that it is in the child's interests to have access to its genetic father's identity should he or she wish to. This interest is held to supersede the wishes of the donor to remain anonymous. This may be a strongly held belief but there are very few data to support it. A comparison is often made with adoption, for which the law was changed recently to allow children who have been adopted to seek out the woman who gave birth to them - their genetic mother. ${ }^{9}$ This does not, however, by right enable the child to seek its genetic father, and this 
information may be available only by courtesy of the mother. Indeed, in some cases she may not know the identity of the child's father herself. Furthermore, although it has been said that children are strongly motivated to seek their genetic roots, since the law on adoption came into force less than $5 \%$ of adopted children have taken up this right.

The comparison with donor insemination has a further flaw. Whereas it is absolutely clear who the mother of a child is - by virtue of her having given birth - paternity after donor insemination cannot be established so clearly. It may be reasonable to assume that the child born in the cycle in which donor insemination was practised is indeed the genetic child of the donor, but this conclusion is not inevitable for two reasons. Firstly, it is possible that during that cycle the woman could have had unprotected intercourse with another man (not her husband) who could then have provided the fertilising sperm. In this case neither the donor nor the husband would be the genetic father. Secondly, donor insemination is used most often in cases in which the male has oligozoospermia - that is, he has spermatozoa, albeit of poor quality. Thus it cannot be assumed that the child's genetic father is the donor - it could be the husband. In both of these cases only careful genetic fingerprinting of the donor, the father, and the child can establish paternity. ${ }^{10}$ It is unlikely that the donor or the father can be subjected forcibly to this test, but unless they are tested no certainty of paternity exists.

One further and worrying implication arises. For a proportion of the population a child believed to be the product of a marriage is not in fact the child of the husband but results from some other sexual liaison. If a child believed to be born after donor insemination has the right to request genetic testing of its social father and the putative donor then presumably all naturally conceived children may demand to have their own father tested to confirm paternity. That would open the floodgates to a practice that would be very destructive to the family.

Finally, and perhaps most importantly, if donor anonymity is lost men will be inhibited from coming forward as sperm donors. Recruitment of donors is becoming increasingly difficult already because of the stringent testing procedures. The loss of anonymity is likely further to reduce the availability of men who are willing to be donors. This has already occurred in Sweden, where the law was changed to allow donors to be named. The donor population has been reduced dramatically, " and patients from Sweden come to Britain to receive donor insemination. If the law is passed as it stands, without protecting donor anonymity, many British women will simply go elsewhere for donor insemination or, more worryingly, will try to procure insemination from unlicensed practitioners. Both of these eventualities will increase the risks of infection with HIV, hepatitis, and other sexually transmitted diseases and defeat any intentions of collecting reliable statistics about donor insemination. ${ }^{12} \mathrm{We}$ must question whether women need to be exposed to these risks and whether a service that enables many thousands of infertile couples to have a family should be lost because of a loosely worded law that makes provision only for non-verified information. And though at present oocyte and embryo donation are practised on a much smaller scale than sperm donation these practices also raise similar issues of donor anonymity.

\section{GIFT}

The second major ambiguity is whether or not the bill as now drafted covers gamete intrafallopian transfer (GIFT) ${ }^{13}$ and therefore requires this procedure to be licensed. When the bill was being considered in the House of Lords doubts were expressed about the suitability of the definition of an embryo in clause 1. An embryo was defined as being present only when the process of fertilisation had been completed with the appearance of a two cell zygote. To acknowledge concern about this definition the government amended clause (b) of the bill to read "references to an embryo include an egg in the process of fertilisation and, for this purpose, fertilisation is not complete until the appearance of a two cell zygote." ${ }_{1+4}$ It was in this form that the bill left the Commons committee. Fertilisation is the process by which the sperm and egg interact to produce the zygote. The bill, as redrafted, defines the end of this process but leaves open the question of when, in law, this process of interaction starts. What stages of interaction are there to be considered? ${ }^{15}$

The first contact made by the sperm will generally be with the cumulus cells surrounding the egg. There may, however, be only a few cumulus cells, and they are also dispersed readily by spermatozoa. In some cases of oligozoospermia the clinician may disperse the cumulus cells mechanically or enzymatically to enhance the approach of the sperm to the egg in GIFT. The next contact made by the sperm is with the zona pellucida, to which it binds through the zona glycoprotein ZP3. ${ }^{16}$ This contact provides species specificity at fertilisation and can occur rapidly in vitro, especially if the zona is wholly or partly denuded of cumulus cells. The third step in the fertilisation process is penetration of the spermatozoon through the zona pellucida into the subzonal perivitelline space between the zona and the egg itself, a process in which specific molecular interactions occur between the spermatozoon and another zona glycoprotein (ZP2). ${ }^{16} \mathrm{Next}$, the sperm attaches to the surface of the egg and fusion of the two cell membranes occurs, the contents of the sperm entering the cytoplasm of the egg. Finally, the second polar body is ejected from the egg, and the approximation of the chromosomes of egg and sperm occurs. DNA is replicated, and eventually the two sets of chromosomes come together on the first mitotic spindle.

In the absence of a clear legal definition of when the process of fertilisation is held to have started it would be difficult to be sure that the process of fertilisation had not begun from the moment of mixing of egg and sperm, as occurs in GIFT. It is insufficient when taking up sperm into the catheter to separate them from the egg by an air bubble ${ }^{13}$ as experience suggests such a separation to be functionally incomplete. Whether or not the penetration of sperm through the cumulus mass is regarded as being integral to, or a prerequisite for, fertilisation there can be much less doubt that from the moment that the sperm binds to the zona a specific fertilisation process is clearly underway. Such binding can occur very rapidly, certainly within the time span occupied by taking the sperm and egg into the GIFT transfer catheter, the insertion of the catheter into the oviduct, and the expulsion of its contents into the oviduct. There may be delays during these processes, and indeed on occasion the catheter may have to be withdrawn and the contents expelled into a culture dish before being taken up a second time. It is inevitable that in some GIFT procedures zona binding and penetration will occur. In such circumstances the process of fertilisation may have started and an unlicensed procedure, subject to the criminal law, been undertaken. We therefore suggest that as for any GIFT procedure there is an appreciable risk of an embryo, as defined in the bill, being present: the bill, as currently drafted, must be assumed to include all GIFT procedures. Many people may believe that GIFT should be licensed and linked to the practice of in vitro fertilisation ${ }^{17}$ but the present uncertainty is unsatisfactory and could lay practitioners open to prosecution for unlicensed activities.

On both this issue and that of donor anonymity practitioners 
of assisted conception and their patients can reasonably ask for a clearer statement from parliament.

PETER BRAUDE

Consultant Lecturer

MARTIN H JOHNSON

Reader in Experimental Embryology

University of Cambridge,

Cambridge

R JOHN AITKEN Senior Scientis

MRC Reproductive Biology Unit, Edinburgh

1 Comhaire FH, Schoonjans FA, Rombaut E, Rose PJ, Farley TT. The history of male infertility and computer assisted management of the infertile male. In: Barrat CLR, Cooke ID, eds Advances computer assisted management of the infertile male. In : Ba

2 Barratt CLR, Monteiro EF, Chauhan M, Cooke S, Cooke ID. Screening donors for sexually transmitted disease in donor insemination clinics in the UK. A survey. Br 7 Obstet (iynaecol 1989;96:461-6.

3 Le Lannou D, Lansac J. Artificial procreation with frozen donor semen: experience of the French Federation CECOS. Hum Reprod 1989;4:757-6

4 Peterson EP, Moghissi KS, Paulden A, Lipschultz LI. New guidelines for the use of semen dono insemination. Fertil Steril 1990;53(suppl 3):399-400

Department of Health and Social Security. Report of the committee of inquiry into human fertilization and embryology. London: DHSS, 1985.

6 Standing Committee on Human Fertilisation and Embryology Bill. House of Commons Official Report 1990 May 15 , cols 192-201

Snowden R, Mitchell GD. The artificial family. London: Unwin Paperbacks, 1983.

8 Walker A, Gregson S, McLaughlin E. Attitudes towards donor insemination-a post-Warnock surgery. Hum Reprod 1987;2:745-50.

9 Snowden R. The social implications of artificial reproduction. In: Thompson W, Joyce DN Newton JR, eds. In vitro fertilisation and donor insemination. London: Royal College of 1985:319-28.

10 Jeffreys AJ, Brookfield JFY, Semeonoff R. Positive identification of an immigration test case using human DNA fingerprints. Nature 1987;317:818-9.

11 Bydgeman M. Swedish law concerning insemination. IPPF Medical Bulletin 1989;23:3-4

12 Barratt CL, Cooke ID. Risks of donor insemination. Br Med f 1989;299: 1178-9.

3 Asch RH, Balmaceda JP, Ellsworth LR, Wong PC. Gamete intra-fallopian transfer (GIFT): a new treatment for infertility. Int $\mathcal{F}$ Fertil 1985;30:41-5.

14 Report stage of Human Fertilisation and Embryology Bill. House of Lords Official Report (Hansard) 1990 March 6;516: No 50, 51 .

15 Johnson MH, Everitt BJ. Essential reproduction. 3rd ed. Oxford: Blackwell Scientific. 1989.

16 Wassarman PM. Early events in mammalian fertilization. Annu Rev Cell Biol 1987;3:109-42.

17 Voluntary Licensing Authority for Human Fertilisation and Embryology. Fourth report. London: Medical Research Council, 1989.

\section{Desensitisation today}

\section{A specialist procedure with few indications}

Desensitisation (hyposensitisation or immunotherapy) was introduced as a revolutionary treatment for allergic disorders in 1911 by Noon. ' Enthusiasm for this treatment has never been high in Britain because of conflicting reports of its efficacy and concern about its possible dangers. ${ }^{2}$ Recently the Committee on Safety of Medicines focused attention on these issues, ${ }^{3}$ stimulating two working groups-the European Academy of Allergy and Clinical Immunology and the World Health Organisation/International Union of Immunological Societies-to publish recommendations on the use of immunotherapy..$^{+5}$ Both have emphasised that it should be carried out only by highly trained medical staff in specialist centres with immediate access to facilities for cardiopulmonary resuscitation and that very strict selection criteria are necessary.

Immunotherapy is indicated exclusively in conditions mediated by IgE. The least controversial indications are well documented anaphylactic reactions to insect stings, as these reactions are life threatening and the vaccines are of proved efficacy ${ }^{67}{ }^{6}$ Desensitisation to a drug may be warranted on the rare occasions when a hypersensitivity reaction has developed and its continued use is considered essential. ${ }^{+5}$ By contrast, immunotherapy is rarely indicated for either asthma or rhinoconjunctivitis as its efficacy is very variable, and acceptable results can almost always be achieved with conventional treatment allied to avoiding the provocative factor. This applies particularly in cases of food and pet allergies. ${ }^{2+5}$
Little is known about the mechanisms by which immunotherapy achieves its results. For insect stings the action probably depends on raising the titre of IgG "blocking" antibodies, which prevent the allergen binding to specific IgE on the mast cells, ${ }^{7}$ whereas in drug hypersensitivity the treatment acts through hapten inhibition. ${ }^{8}$ The mechanisms in other types of immunotherapy remain puzzling, given that IgG titres often correlate poorly with apparent efficacy. There is, however, a modest rise in $\mathrm{IgE}$ concentration late in treatment. ${ }^{910}$ This may be a consequence of induction of suppressor T lymphocytes, whose concentrations are low in people with asthma..$^{10-12}$ The abnormally high serum concentrations of neutrophil and eosinophil chemotactic factors found in patients with asthma, particularly during early and late phase responses to inhaled antigen, are reduced after immunotherapy,,$^{1314}$ and the late response itself is frequently abolished. ${ }^{15}$

In clinical practice the results of immunotherapy depend on the patient's age and on the condition treated. Better results are obtained in children than adults and in people with rhinitis than in those with asthma, in which the efficacy of immunotherapy is inversely related to the severity of the condition. ${ }^{16}$ Efficacy is improved by giving single allergen vaccines to treat a single allergy and by giving the highest possible maintenance dose of antigen. ${ }^{+51718}$ The most successful immunotherapy is with pollen extracts and the least effective with bacteria. The efficacy of desensitisation to moulds and candida remains unproved. ${ }^{+5}$ These differences in efficacy may reflect the greater advances made in the standardisation and characterisation of extracts of pollens, Dermatophagoides pteronyssinus, and dog dander when compared with other vaccines.

An unfortunate consequence of improving the purity of extracts has been the increase in severity of side effects during immunotherapy, since these also depend on the dose. ${ }^{+51819}$ Though sustained release and depot preparations reduce the incidence of adverse effects by decreasing the bioavailability of vaccines, ${ }^{20}$ disappointing results have been obtained from allergoids-antigen extracts modified by formalin or by ultraviolet rays to reduce "allergenicity" while retaining "immunogenicity." "21 Finally, in some patients in whom desensitisation to insect stings has been abandoned because of intolerable side effects, pretreatment with specific venom IgG from beekeepers' serum samples allowed them to tolerate full "rush" desensitisation courses with between 500 and 800 times the previous tolerable dose. ${ }^{22} 23$ Bee venom IgG produced an influenza-like syndrome in 15 of the 25 patients, but the active immunotherapy with bee venom produced no systemic effects in 21 of them. This combination of active and passive immunotherapy seems to be a reasonable option for desensitisation to Hymenoptera species.

At present, therefore, the verdict on immunotherapy is that it is a highly specialised procedure with few indications, a high morbidity, and an appreciable mortality..$^{2.5}$ Few centres in England possess the necessary facilities and skill to contemplate undertaking immunotherapy with equanimity. Unless major advances are made few patients should be submitted to this treatment; even its enthusiasts consider it the final therapeutic approach. ${ }^{18}$

Consultant Physician, Chest Clinic,

NOEMI EISER

Lewisham Hospital, London SE13 6LH

1 Noon L. Prophylactic inoculation against havfever. Lancet 1911;i:1572-3.

2 Grant IWB. Does immunotherapy have a role in the treatment of asthma? Clin Allergy 1986;16: $7-16$.

3 Committee on Safery of Drugs. Committee on Safety of Drugs Update. Desensitising vaccines. Br.Med 7 1986;293:948.

4 European Academy of Allergology and Clinical Immunology Immunotherapy Subcommittee. Immunotherapy: position paper. Allergy 1988;43 (suppl 6):9-33.

5 World Health Organisation/International Union of Immunological Societies Working Group Current status of allergen immunotherapy. Lancet 1989;i:259-61. 